\title{
INCENTIVES IN UNIVERSITY TECHNOLOGY TRANSFERS ${ }^{\dagger}$ Inés Macho-Stadler ${ }^{\ddagger}$ \& David Pérez-Castrillo ${ }^{\S}$ Universitat Autònoma de Barcelona
}

\begin{abstract}
There are two main ways in which the knowledge created in universities has been transferred to firms: licensing agreements and the creation of spin-offs. In this paper, we describe the main steps in the transfer of university innovations, the main incentive issues that appear in this process, and the contractual solutions proposed to address them.
\end{abstract}

\footnotetext{
${ }^{\dagger}$ We gratefully acknowledge the financial support from 2009-07616ECON, 2009SGR-169 and ICREA Academia.

₹ Dep. of Economics \& CODE, Universitat Autònoma de Barcelona. Email: ines.macho@uab.es

$\S$ Corresponding author. Dep. of Economics \& CODE, Universitat Autònoma de Barcelona, 08193 Bellaterra (Barcelona), Spain. Email: david.perez@uab.es. Ph.: (34) 935811405 and (34) 93581 2461. Fax: (34) 93 581 3767.
} 


\section{Introduction}

There is a large and growing interest in the organization of the transfer of scientific knowledge created by universities to the private sector. Many highly innovative sectors such as robotics, electronics and the live sciences benefit from the results of university research. For example, Cockburn and Henderson (1998) calculate that research carried out in public institutions was used in 16 out of 21 medicines that, according to experts, have enjoyed the greatest therapeutic impact between 1965 and 1992.

There are two main ways in which the knowledge created in universities has been transferred to firms. The prevailing way is through licensing agreements; the groundbreaking way involves the creation of spin-offs. The empirical literature (Meyer, 2006) indicates that for a university, the option of creating a spin-off is, and indeed should be, the exception rather than the rule. University Technology Transfer Offices (TTOs), even successful ones, also express a clear preference for licensing contracts to channel the transfer of technology generated within universities. One important reason is that spin-off deals are much more complex to write and manage than licensing agreements. Often, a TTO starts a spin-off because an innovation is too embryonic to be easily developed and integrated inside a firm.

In this paper, we describe the main steps in the transfer of university innovations, the main incentive issues that appear in this process, and the contractual solutions proposed to address them. In this manner, we also provide a short and necessarily biased review of papers that analyze contractual solutions to asymmetric information problems in licensing and venture capital contracts. Our main objective is to clearly state the main problems and solutions rather than to provide a comprehensive review of the literature.

\section{University licensing contracts}

University licensing contracts have many features in common with other licensing 
agreements, with two important caveats. First, most university innovations require further development to be practically applicable, and thus, the involvement of the researcher (or the research team) responsible for the innovation is usually necessary for the success of early development phases. Second, a university never commercializes the final product; hence, it will not compete with a subsequent licensee in the product market.

The two main elements of university licensing contracts are royalties and fixed fees. Royalties are payments that vary according to the quantity produced and sold using the new technology. They have the inconvenience of artificially increasing the licensee's perceived marginal production cost. Therefore, the licensee will not increase its production as much as it otherwise would. Independent of the activities of the licensee once a new technology is incorporated, a fixed payment does not have this distorting effect, and outside of other considerations, it is in principle the optimal payment instrument to license a technology.

A common argument in favor of payments that vary with the licensee's output is that they allow risk sharing when revenues are uncertain, since it is difficult to anticipate the new production costs or product demand. If both the licensor and the licensee are risk-averse, then sharing revenues can be an efficient insurance mechanism; see the analysis of Bousquet, Cremer, Ivaldi and Wolkowiz (1998). In what follows, we shall ignore this risksharing aspect to concentrate on the incentive characteristics of the contract terms.

Figure 1 depicts the main decisions involved in a university-licensing contract; we distinguish between the development and commercialization stages. Note that $\mathrm{R}$ refers to the researcher, or the research team, and F refers to the firm. 


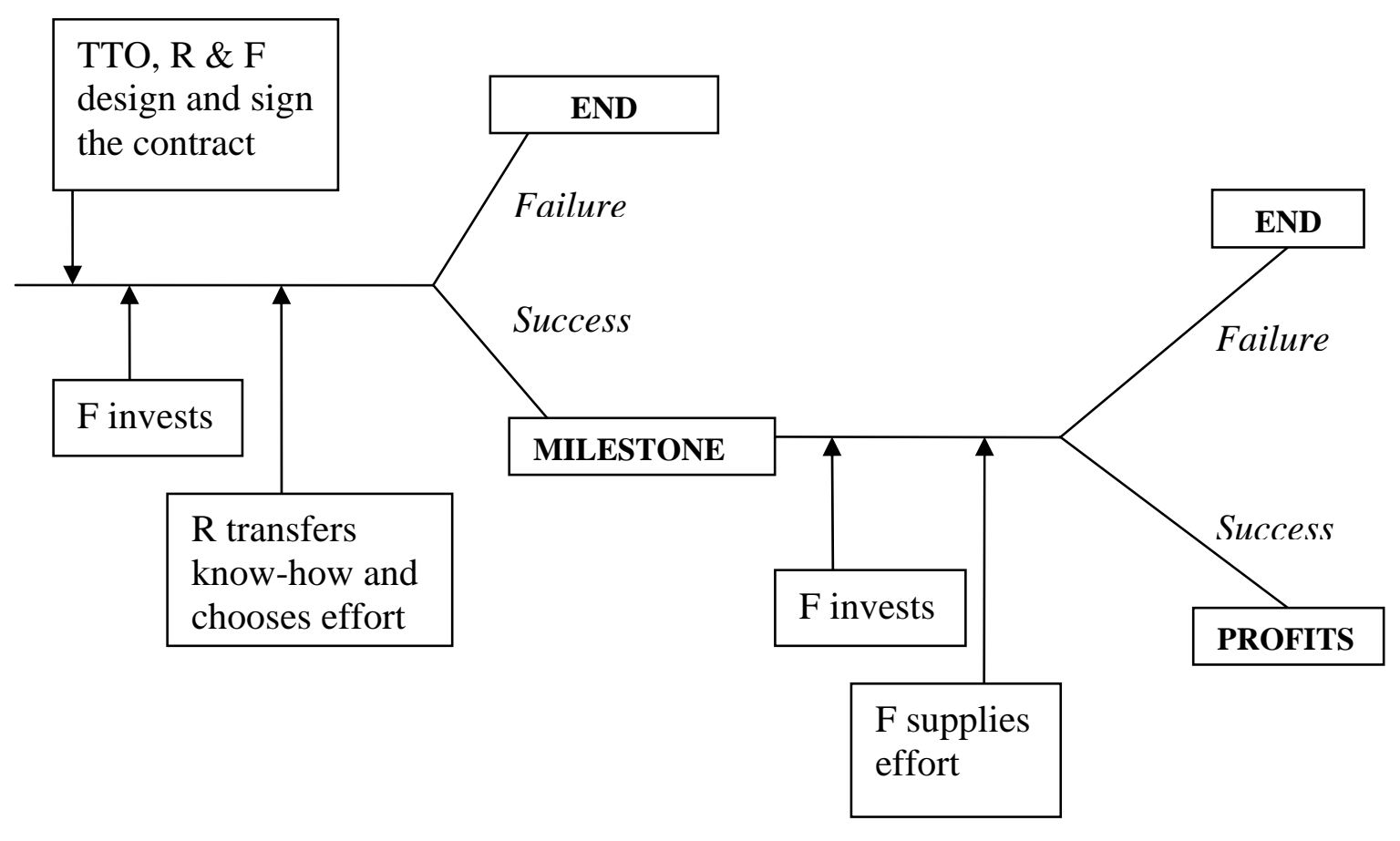

Figure 1: Patent licensing with development and commercialization stages

We begin by considering the moment at which the university (that is, the TTO and/or the researcher) and the firm design the contract. At this point, two possible informational problems can appear. First, the description of the innovation may not be rich enough to estimate its value, and thus the details of the discovery may not be publicly described. This may be because such a description would allow the innovation to be easily imitated, as happens once the logic behind a magic trick is revealed. Alternatively, there may be no patent that protects the technology that has been discovered. Obviously, a firm is willing to pay more for a more valuable innovation, and so the TTO has an interest in suggesting that it has a path-breaking discovery. If the university is better informed than the firm as to the value of the innovation, it can use royalties to signal the value of the innovation (Gallini and Wright, 1990, Macho-Stadler and Pérez-Castrillo, 1991). Indeed, under fixed payment, the TTO receives its money up front, independently of the firm's revenues, while under a 
variable payment, the amount depends upon firm production. Hence, royalties link the TTO's profits to the value of the innovation, and thus, their inclusion signals a high-quality innovation.

Second, it may also be the case that the firm is better informed than the TTO. Firms are in a much better position than the university to know market opportunities and the potential use of new technologies. In fact, universities are typically poorly informed about markets in general, and hence, they face an adverse selection problem. In this case, the licensee may claim that a patent has a low commercial value to obtain a low fee. The TTO thus must design a "menu" of contracts from which a firm chooses, thereby revealing its level of information. Macho-Stadler and Pérez-Castrillo (1991) show that a royalty should be included in the contract designed for an innovation with high commercial value, while a low-valued discovery should be licensed through a fixed fee. For a firm that places a high value on a patent, a royalty is costly, and so it would prefer a fixed payment contract. The contrary is true for a firm that places a low value on the patent; in this case, a royalty scheme is better since the firm will presumably produce and sell few units.

Once a contract is signed, the development stage starts. The innovation is developed by the firm (and usually, inside the firm). However, the collaboration of the innovator is crucial to extract all the value of the innovation and thus adequately develop the new technology. Indeed, either the innovation that is provided by university licenses is at an embryonic stage (i.e., at a "proof of concept" stage), or only a laboratory prototype is available. Further development requires (or it is facilitated by) additional knowledge, an important part of which cannot be included in the patent description or the contract. The process of obtaining an innovation produces expertise or know-how, which may be vital for its development. The problems solved, the errors made, the strategies pursuit, and the intuitions built up during the innovation process are neither patentable nor publishable, but they are very useful to the development of the technology. However, it is difficult to commit to the transfer of this know-how. The inclusion of royalties in a contract provides incentives to this transfer, as the amount received by the university increases with the licensee's revenues. We should then expect the presence of royalties to be positively correlated with the transfer of know-how 
(Macho-Stadler, Martínez-Giralt and Pérez-Castrillo, 1996). Due to similar reasons, royalties also provide incentives to innovators to collaborate in the development of the innovation. Therefore, the more such collaboration is needed or the more embryonic the innovation is, the more likely we are to see royalties included in the licensing contract (Jensen and Thursby, 2001).

Royalties are not the only way to structure a variable payment system. Holding shares or equity in the firm is an alternative way to make payments depend on the success of the new technology. The advantage of shareholding is that it does not distort firm costs and also works as a risk-sharing mechanism. However, in most cases, the licensed technology has a limited impact on overall firm profits; hence, most of the variation in these profits does not actually reflect the value of the new technology, which decreases the incentive properties of holding shares. Thus, shareholding is likely to appear only when the licensed technology is the core business of a small firm. Payments based on milestones, when they can be verified, may also be an attractive alternative to royalties, since they also do not distort output (Dechenaux, Thursby and Thursby, 2009b).

In the development stage, one must also take into account the potential moral hazard concerning a firm's allocation of funds and human resources during the development stage. Given that this stage is often carried out within a firm, it may be difficult for a third party to verify the firm's decisions. If this contract is heavily based on royalties (or equity or milestones), then part of the earnings will go to the university, and the firm will have less interest in the success of this development stage. This leads to a trade-off, since the incentives that are needed to motivate the innovator and the firm move in opposite directions. An optimal licensing contract must balance the incentive effects of royalties or milestones for both the firm and the university researcher.

Payments based on milestones, particularly technical milestones, may have additional advantages when the commercialization stage is taken into account. In this stage, the input from the researcher is usually not necessary (or is not crucial), while the main decisions come from the firm. Therefore, an optimal contract would require the university to not be 
involved in payments starting at the commercialization stage. This can be achieved if all conditional payments to the university are made before this stage. Payments based on technical milestones (i.e., on the success of the development stage), when feasible, may be more efficient from an incentive point of view than payments based on commercial success like royalties or equity shares (Dechenaux, Thursby and Thursby, 2009a).

Finally, early payments to the university and the inventor, including up-front fees, as well as annual fees that make it costly for a firm to keep a technology may be necessary to make sure that the licensee signs the contract with the intention to use the technology. This may prevent situations in which the firm wants to license an invention with the only objective of shelving it in case of success; for example, it may want to prevent competitors from accessing the technology (Dechenaux, Thursby and Thursby, 2009a).

\section{University spin-offs}

University spin-offs constitute the entrepreneurial route to commercializing public research. They are initiated either directly by the researcher (or laboratory) that made the discovery or by the university's TTO. A spin-off agreement involves the TTO and the researcher as well as one outside financer, that is, either a venture capitalist (VC) or a business angel (BA). VCs are "formal” early-stage investors that create funds that pool and manage money. BAs are "informal" wealthy individuals that invest their own funds in a small set of new business ventures. Given that spin-offs take time to become profitable and lack tangible assets, debt financing by banks is typically not an option.

Spin-off contracts are more complex than licensing agreements. They allocate both cash flow rights and control rights, the latter of which may or may not be associated with cash flow rights, to the main participants (i.e., the TTO, researcher and VC or BA) and possibly also to the manager who will be hired to run the venture. It is customary to distinguish two types of shares, namely, financial shares, which are directly related to the capital invested, and founder shares, which compensate for the intellectual property brought in by the researcher(s) and owned by the university’s TTO. 
The very high level of scientific, financial and commercial uncertainty implies that each step in the venture may lead to the renegotiation of the previous contract and/or an increase in the financing of the spin-off; new financial shares may be issued, and new partners may be included. Also, a successful spin-off must decide its exit strategy either through acquisition by an existing company or through an Initial Public Offering (IPO). Given the different objectives that the participants in such contracts usually have, each renegotiation generates conflict, since decisions that benefit one participant do not necessarily benefit all.

Figure 2 sketches the main elements in terms of decisions or information along the timeline of a typical spin-off. We have distinguished three stages, namely, the development stage, the commercial stage, and the exit stage. The major conflicts of interest happen between the financier(s) on one side and the researcher, and possibly the manager on the other side. The TTO is aligned with the financier with respect to some issues, but it is aligned with the researcher in other issues. To simplify, in the Figure 2 we denote the researcher together with the manager by $\mathrm{R}$, even though the manager does not intervene in the initial contract.

\section{DEVELOPMENT STAGE}

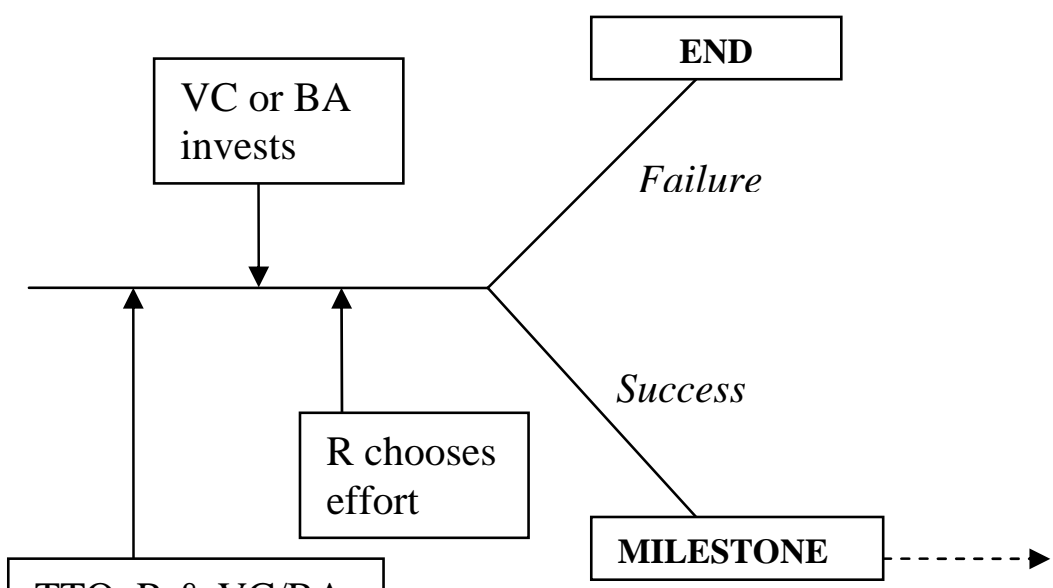

TTO, R \& VC/BA design and sign the contract 


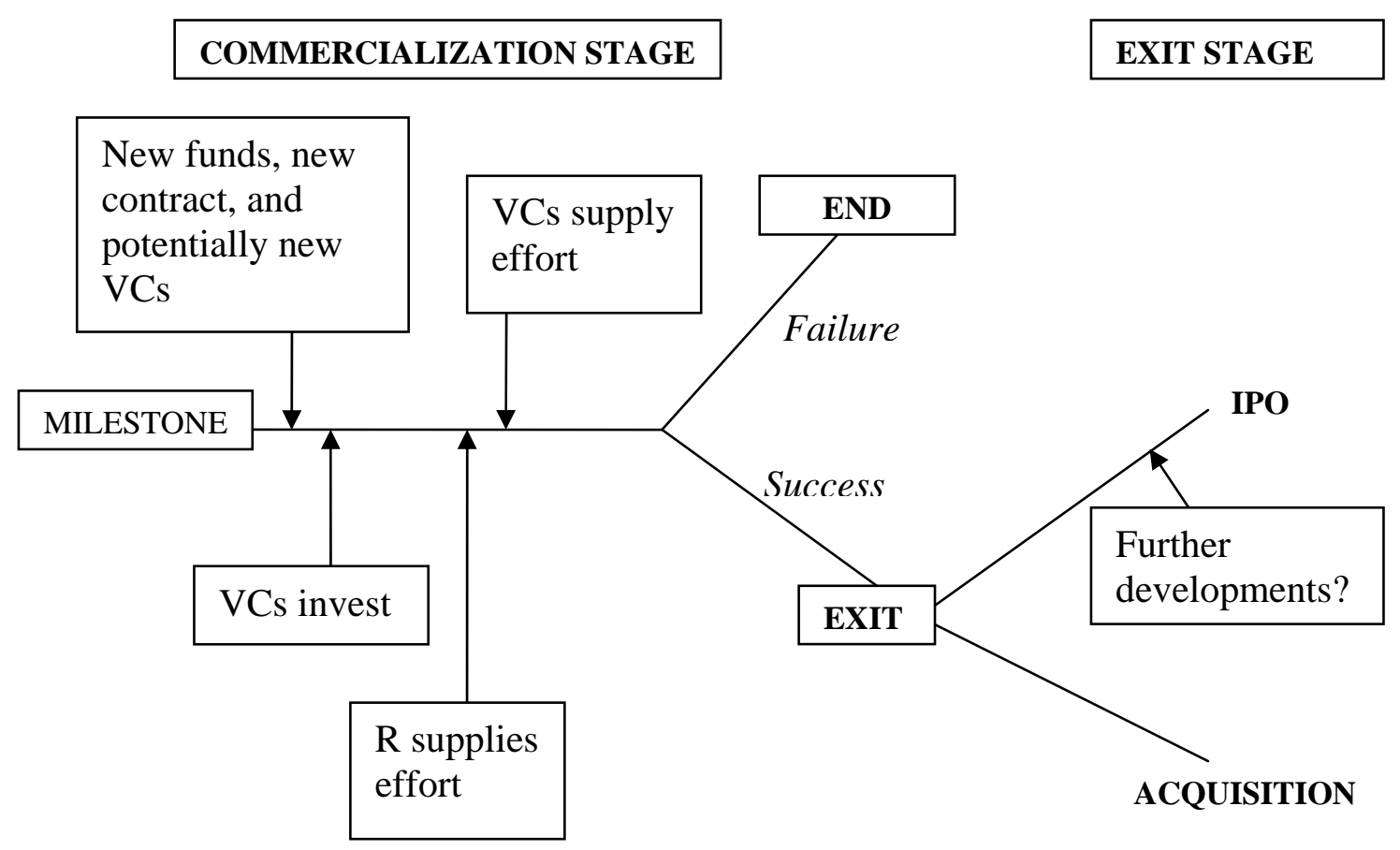

Figure 2: Spin-off with development, commercialization and exit stages

The first problem encountered when forming a spin-off, that is, reaching a beneficial agreement among all parties, involves assessing the expected profitability of the project. It is very likely that the researcher is better equipped to evaluate the scientific value and existing know-how than the financier. Most BAs and VCs lack the required expertise in science and engineering to make an adequate assessment. They may choose to engage in detailed scrutiny of all aspects of the proposal, but the costs of such an evaluation are often large compared to the level of investment required at this stage. Additionally, VCs and BAs have better knowledge about the whole process of commercialization, including the steps and difficulties that may be encountered and the potential commercial value in case of success. However, the best-informed participant may very well be the TTO. A good TTO has personnel who know about the scientific content of the innovation, and at the same time, it is in contact with the markets, which allows it to assess the potential commercial value of the invention. If this is the case, the TTO can "signal” profitable projects by taking financial stakes in them (Macho-Stadler, Pérez-Castrillo and Veugelers, 2008). Although having the 
TTO financing is usually inefficient, given the difficulties TTOs usually encounter in raising funds, it is a good way to signal precisely because it is so costly. Hence, TTOs can own both founder and financial shares in some ventures.

There are other ways to signal the profitability of a project. Many TTOs have no cash to invest; even if they do, they may prefer other ways to signal profitability or to complement or reinforce the signal sent through TTO financing with other signals. Kaplan and Strömberg (2003) argue that the ubiquitous presence of various types of convertible preferred stocks in the hands of VCs can be explained as a way to persuade VCs regarding the profitability of the project. Convertible preferred stocks are senior shares; hence, VCs typically receive everything in the case that the final value of the venture is not large. By maintaining junior claims, the researcher (and often the TTO) evidences confidence that the innovation is a real breakthrough with real chances to provide large profits.

Finally, the inclusion in the contract of so-called "anti-dilution clauses" also helps to signal to financiers that no bad surprises are expected. These clauses allocate the incumbent investors additional shares during subsequent financing if the estimated value of the project is more negative and the price of the new issue is lower than their current values.

Once a contract is signed and an investment is made according to contract (the investment is a verifiable variable), the major issue during the development stage is ensuring that the researcher and the entrepreneur engage in appropriate effort and decisions. At this stage, the non-financial contribution of the $\mathrm{VC}$ or BA does not seem as important as in the commercialization and exit stages; still, these partners may play a crucial role, for example, in the identification of a good management team. Researchers and managers obtain incentives through their participation in the company. A good part of their payment is in terms of shares, the number of which can increase as milestones are reached. It may also be the case that these actors take a (sometimes small) financial stake in the spin-off to reinforce their commitment. Moreover, in most cases the incentives of these participants are even stronger than suggested by their shares, as they hold claims that are junior to VC claims. Therefore, they have incentives to engage in ambitious projects. 
The continuing presence of both the researcher and the manager is so crucial that most spinoff contracts include clauses that make it costly for them to leave the venture (thus taking their human capital with them) once the project has started. Their shares are often vested over time so that a participant who leaves the spin-off receives only a part of his/her entitlement. Also, non-compete clauses prohibit them from working for a company with similar interests and in which their human capital may be more valuable for a certain period of time.

There are other instruments that provide appropriate incentives for researchers and managers. First, financing during the development phase is often staged so that projects that are doomed to fail are not continued (Gompers, 1992). Staged financing also allows the financier to maintain some bargaining power at a stage in which the roles of researchers and entrepreneurs are so critical that these parties may try to renegotiate down an investor's claim once an investment has been made (Neher, 1999). Second, anti-dilution clauses also provide incentives for completing the development phase with good prospects, as the relative shareholdings of researchers and entrepreneurs decrease given the increase in the number of shares of the current financier if the valuation of the venture is low.

A crucial moment in the life of a spin-off is reached when the development stage has finished. If this milestone has been successfully accomplished, the next commercialization stage typically requires substantially more financing. The incumbent financier may not have the resources or the willingness to risk the large amount of investment necessary at this point in the venture. In any case, it is efficient in most situations that new financiers share risks with insiders. It is then necessary to value the firm so that a fair price in terms of shares is allocated to those bringing new money into the venture. However, insiders (i.e., researchers, managers, incumbent financiers and the TTO) have more accurate information than outsiders (i.e., new financiers) concerning firm assets; hence, a new asymmetric information problem emerges. This may not be the only relevant problem, as conflicts may arise among insiders. For example, the incumbent financier may have different objectives and tools than other participants. 
As was the case when the spin-off was constituted, offering convertible preferred stocks to new financiers helps convince them of the profitability of the project; that is, offering senior claims signals projects with good prospects. The second signaling device is the further involvement of current participants, mainly the incumbent financier, in the venture. The situation here may be different depending on whether the first financier was a VC or a BA. Indeed, a VC has many more resources than a typical BA; hence, although it may not be efficient from a risk-sharing point of view, a VC has the possibility to cover a substantial fraction of the required additional financing. This constitutes one advantage of the involvement of a VC instead of a BA in the initial contract. However, this potential advantage can become a double-edged sword, as it provides the VC with strong bargaining power over the other participants that can be used to renegotiate the initial contract. The anticipation of this "hold-up” problem may be very negative for the spin-off and, thus, also for the VC, since the incentives of researchers and managers to provide adequate time, effort, and resources in the development stage may be seriously compromised.

Also, when the involvement of an incumbent financier in a new financing round is large, his/her interests may no longer be aligned with those of the rest of the participants. Indeed, while researchers, managers and the TTO are clearly interested in fixing a high price for the new stock (that is, offering few shares per Euro), the incumbent financier may prefer a low price if he/she will be covering a large part of the new financing, as this dilutes the stakes of the other participants. Fluck, Garrison and Myers (2006) argue that an ex-ante commitment to the syndication of later stages of financing may align a VC's objectives with the interests of the other participants, since it precludes the incumbent VC from being a disproportionately large investor in subsequent financing rounds. Hence, syndication reduces the hold-up problem, which may explain why most later-stage VC investments are syndicated.

The commercialization stage combines a need for further scientific and technical development of the product with a substantial advance in its commercialization. The involvement of the researcher is still important at this point, but input from the VCs (and BAs, if applicable) is also crucial, as they provide services such as the evaluation of business 
opportunities, growth strategies, tracking and coaching of the company, identification of suppliers and other stakeholders and, later on, the preparation and execution of an exit strategy. Therefore, the moral hazard problem for VCs may be severe.

In fact, the need for external advice may explain the financial involvement of VCs and/or BAs even in those few cases in which researchers and management (possibly together with the TTO) are able to fund the entire investment (Casamatta, 2003). The reason is that the financial participation of VCs and/or BAs provides them with incentives to supply services to the venture that would otherwise need to be provided by an external consultant requiring a high informational rent. Therefore, projects requiring a relatively small level of investment are optimally fully financed by VCs and/or BAs, while the financial involvement of researchers and management would be optimal if the required investment is large so that they also have the right incentives to engage in the project. Finally, an optimal contract must provide fair compensation to the financiers; hence, it allocates convertible bonds or preferred equity to them if the amount they invest is large; otherwise, manager and researcher are given preferred equity, and VCs and BAs receive common stocks.

Stocks usually cannot provide the right incentives to all participants in a spin-off: to fully internalize the effects of his/her decisions, each participant would need to receive all shares. However, the convertible feature of securities that often appear in venture capital contracts has powerful incentive properties when the main decisions of the entrepreneur and/or researcher are made before those decisions made by financiers (Schmidt, 2003). In an optimally drafted contract, financiers will exert their conversion (i.e., debt-to-stock) rights if and only if they take adequate investment and service decisions. Given that these decisions are crucial to the success of the spin-off, entrepreneurs have incentives to take the actions that will push investors to convert and thus make the right decisions.

If efforts by entrepreneurs and financiers are not sequential but simultaneous, the incentive properties of the convertible securities disappear. Then it is optimal to reward the VCs only when the profitability of the project has reached a certain level, which can achieved through warrants that yield positive payoff only if the firm value exceeds the strike price. See 
Repullo and Suarez (2004), who assume that such efforts are complementary. However, this type of warrant does not seem to be common in venture capital contracts according to Kaplan and Strömberg (2003).

The final stage of a successful spin-off is the exit, at which point the venture either is acquired or remains independent and moves through an IPO. All the main participants in the venture typically own a high number of shares of the company; hence, they have the common interest of maximizing its exit value. However, they also have conflicting objectives due to several reasons, which makes it difficult to design contracts that lead to an efficient exit decision.

First, VC firms, especially young VC firms, have incentives to grandstand; that is, they take actions that signal their capacities to potential investors, in particular by bringing companies public too early, which leads to underpricing, to raise their profiles and raise capital for new funds (Gompers, 1996). This conflict of interest among spin-off participants is also documented by Chahine, Filatotchev and Wright (2007), who show that VC behavior in IPOs is different from BA behavior. In their sample, initial underpricing is positively related to VC-retained ownership, but it is negatively related to BA-retained ownership.

A second source of conflict is that while the main financial contributors (i.e., VCs, BA, and possibly the TTO) are only concerned about monetary returns, the manager (and possibly the researcher) cares about both pecuniary and non-pecuniary returns, such as reputation, specific human capital, maintenance of their position as manager of a publicly listed firm, and so on. A crucial instrument in reaching an efficient exit decision is the allocation of contingent control rights between management and financiers, depending on the profitability (or signals of profitability) of the project (Aghion and Bolton, 1992). In particular, the financiers should obtain decision rights when the expected profitability is low, while management should retain these rights otherwise. The empirical analysis of Kaplan and Strömberg (2003) provides support for this theory.

The different participants in the venture can also face incentive problems if the exit occurs 
under an IPO; that is, further development is necessary at this stage to bring the innovation to the market. Providing the right incentives requires an adequate allocation of shares, which may imply that the manager maintains a large number of shares. How is it then possible to reward the financiers when there is a large funding requirement? The answer is that they should obtain a more than fair compensation in case the optimal exit occurs through an acquisition (see Hellmann, 2006). The contract rewards the financiers through convertible preferred equity with automatic conversion at the IPO; therefore, reward to the financiers is proportionally larger in the case of acquisition. Moreover, to achieve an optimal choice among the exit options, the contract should provide control to the manager if there are good prospects for going public while control must be allocated to financiers if these prospects are not good.

\section{Some concluding thoughts}

In recent years, we have learned much about the consequences and possible remedies of the existence of ubiquitous asymmetric information at all steps of university technology transfers. In this paper, we have highlighted the major incentive problems and how contracts can deal with them. However, there are still many open questions, and thus, further research is necessary to better understand the optimal design of technology transfer agreements. We now comment on a subset of relevant issues.

First, the role played by risk aversion in these contracts is not fully understood, particularly with respect to spin-off contracts. While there is a consensus that the risk involved in these agreements is very large and that even venture capitalists are risk-averse partners, all the models presented here (with the exception of Bousquet et al., 1998) assume that the participants are risk neutral and that some of them are subject to limited liability. This convenient hypothesis is very useful to analyze most incentive problems. However, risk aversion should also play a role in various aspects of contracts such as the type of financiers involved (i.e., VCs or BAs), the number of investors participating in the venture, the timing of funding, the eventual syndication of some of the stages of financing, and so on. 
Second, some of the conflicts of interest that emerge among participants in spin-off deals require further investigation. The dynamic of these contracts implies that partners with objectives aligned today may become antagonists tomorrow. For example, the TTO may be close to the researcher when a contract is designed, but it may be closer to the VCs and BAs when the venture is about to reach an exit strategy. In addition, the harshness of the conflicts of interest may depend on the type of partner; a VC, for instance, may behave differently than a BA. The anticipation of these conflicts may have severe consequences on the incentives of participants in this venture. Although a few papers have analyzed some of these problems, further research should shed additional light on the optimal renegotiation protocols, allocation of control rights, and contract provisions.

Third, many more empirical analyses and case studies are necessary. Very few authors have been able to study in detail licensing and venture capital contracts, and still fewer researchers have access to university contracts. Given their complexity, the meticulous analysis of the allocation of cash flow, voting and control rights, and the provisions and the renegotiations of these contracts would be extremely useful to understand the main problems that they address as well as to propose improvements in the contracts that could help solve these same problems in a more efficient way.

Finally, asymmetric information and incentive issues are so prevalent in university technology transfers, particularly those involving the creation of spin-offs, that the design and management of these contracts thus become complex matters. The existence of a wellorganized TTO that can carry out these tasks adequately as well as the identification of promising innovations, management of intellectual property rights, and so on are crucial for a successful transfer. A good TTO provides services that, if supplied individually by each researcher, department or laboratory, would be quite expensive and/or difficult to finance. It may also allow the university to build up a reputation that it offers only promising innovations while shelving the others (Macho-Stadler, Pérez-Castrillo and Veugelers, 2007). There are a few analyses of TTO performance (Siegel, Wright, Chapple and Lockett, 2008), but very little is known about the organizational characteristics that help TTOs become successful and about the management of TTOs, although one exception with regard to the 
latter is Debackere and Veugelers (2005).

\section{References}

Aghion, P. and P. Bolton, 1992, “An incomplete contracts approach to financial contracting”, Review of Economic Studies 59, 473-494.

Bousquet, A., H. Cremer, M. Ivaldi and M. Wolkowiz, 1998, "Risk sharing in licensing”, International Journal of Industrial Organization 16, 535-554.

Casamatta, C., 2003, "Financing and advising: optimal financial contracts with venture capitalists, Journal of Finance 58, 2059-2086.

Chahine, S., I. Filatotchev and M. Wright, 2007, "Venture capitalists, business angels, and performance of entrepreneurial IPOs in the UK and France", Journal of Business, Finance \& Accounting 34 (3), 505-528.

Cockburn, I. and R. Henderson, 1998, “Absorptive capacity, co-authoring behavior, and the organization and the organization of research in drug discovery", The Journal of Industrial Economics 46 (2), 157-182.

Debackere, K. and R. Veugelers, 2005, "The role of academic technology transfer organizations in improving industry-science links,” Research Policy 34, 321-342.

Dechenaux, D., M. Thursby and J. Thursby, 2009a, “Shirking, sharing risk and shelving: the role of university license contracts”, International Journal of Industrial Organization 27, 80-91.

Dechenaux, D., M. Thursby and J. Thursby, 2009b, "Inventor moral hazard in university licensing: The role of contracts”, WP Georgia Institute of Technology.

Fluck, Z., K. Garrison and S. C. Myers, 2006, "Venture capital contracting: Staged financing and syndication of later-stage investments”, mimeo, MIT Sloan School of Management.

Gallini, N.T. and B.D. Wright, 1990, “Technology transfer under asymmetric information”, Rand Journal of Economics 21, 147-160.

Gompers, P.A., 1992, “The structure of venture capital investment”, Harvard Business School, mimeo.

Hellmann, T., 2006, "IPOs, acquisitions, and the use of convertible securities in venture capital”, Journal of Financial Economics 81, 649-679.

Jensen, R. and M. Thursby, 2001, "Proofs and Prototypes for sale: the licensing of university inventions”, The American Economic Review 91, 240-259. 
Kaplan, S. and P. Strömberg, 2003, "Financial contracting meets the real world: An empirical study of venture capital contracts”, Review of Economic Studies 70, 281-315.

Macho-Stadler, I., X. Martinez-Giralt, and D. Perez-Castrillo, 1996, "The role of information in licensing contract”, Research Policy 25, 25-41.

Macho-Stadler, I. and D. Pérez-Castrillo, 1991, “Contrats de licence et asymétrie d'information”, Annales d'Economie et de Statistique 24, 189-208.

Macho-Stadler I., D. Pérez-Castrillo and R. Veugelers, 2007, "Licensing of university inventions: the role of a Technology Transfer Office”, International Journal of Industrial Organization 25 (3), 483-510.

Macho-Stadler I., D. Pérez-Castrillo and R. Veugelers, 2008, "Designing contracts for University spin-offs”, Journal of Economic and Management Strategy 17, 185-218.

Meyer, M., 2006, “Academic inventiveness and entrepreneurship: On the importance of start-up companies in commercializing academic patents”, Journal of Technology Transfer 31, 501-510.

Neher, D.V., 1999, “Staged financing: An agency perspective”, Review of Economic Studies 66, 255-274.

Repullo, R. and J. Suarez, 2004, "Venture capital finance: A security design approach”, Review of Finance 8, 75-108.

Schmidt, K., 2003, Convertible securities and venture capital finance”, Journal of Finance 58, 1139-1166.

Siegel, D., M. Wright, W. Chapple and A. Lockett, 2008, “Assessing the relative performance of university technology transfer in the US and UK: A stochastic distance function approach”, Economics of Innovation and New Technology 17 (7\&8), 717-729. 